\title{
Microvascular Endothelial Dysfunction and Enhanced Thromboxane and Endothelial Contractility in Patients with HIV
}

Dan Wang $^{1^{*}}$, Joseph K Melancon ${ }^{2}$, Jennifer Verbesey ${ }^{2}$, Haihong Hư ${ }^{3}$, Chenglong Liu ${ }^{3}$, Shakil Aslam ${ }^{1}$, Mary Young ${ }^{3}$ and Christopher S Wilcox ${ }^{1}$

${ }^{1}$ Hypertension, Kidney and Vascular Research Center and the Division of Nephrology and Hypertension, Georgetown University, USA

${ }^{2}$ Transplant Institute, Georgetown University, USA

${ }^{3}$ Division of Infectious Disease and the Metropolitan Washington Women's HIV Study group, Georgetown University, Washington, USA

\section{Abstract}

Background: The prevalence of cardiovascular disease is increased with human immunodeficiency virus (HIV) infection, but the mechanism is unclear. We hypothesized that HIV increases microvascular reactive oxygen species, thereby impairing endothelial function and enhancing contractility.

Method: Subcutaneous microarterioles were isolated from gluteal skin biopsies in premenopausal, African American, HIV positive women receiving effective anti-retroviral therapy, but without cardiovascular risk factors except for increased body mass index $(n=10)$ and healthy matched controls $(n=10)$. The arterioles were mounted on myographs, preconstricted and relaxed with acetylcholine for: endothelium-dependent relaxation, endotheliumdependent relaxation factor (nitric oxide synthase-dependent relaxation), endothelium-dependent hyperpolarizing factor (potassium-channel dependent relaxation) and endothelium-independent relaxation (nitroprusside). Contractions were tested to endothelium-dependent contracting factor (acetylcholine contraction with blocked relaxation); phenylephrine, $\mathrm{U}-46,619$ and endothelin-1. Plasma L-arginine and asymmetric dimethylarginine were measured by high performance capillary electrophoresis.

Results: The micro-arterioles from HIV positive women had significantly $(\%$ change in tension; $\mathrm{P}<0.05)$ reduced acetylcholine relaxation ( $-51 \pm 6$ vs. $-78 \pm 3 \%)$, endothelium-dependent relaxation factor $(-28 \pm 4$ vs. $-39 \pm 3 \%)$, endothelium-dependent hyperpolarizing factor $(-17 \pm 4$ vs. $-37 \pm 4 \%)$ and decreased nitric oxide activity $(0.16 \pm 0.03$ vs. $0.70 \pm 0.16 \Delta$ unit) but unchanged nitroprusside relaxation. They had significantly enhanced endothelium-dependent contracting factor ( $+21 \pm 6$ vs. $+7 \pm 2 \%)$ and contractions to $U-46,619(+164 \pm 10$ vs. $+117 \pm 11 \%)$ and endothelin $-1(+151$ \pm 12 vs. $+97 \pm 9 \%)$, but not to phenylephrine. There was enhanced reactive oxygen species with acetylcholine $(0.11 \pm$ 0.02 vs. $0.05 \pm 0.01 \Delta$ unit; $P<0.05)$ and endothelin- 1 ( $0.31 \pm 0.06$ vs. $0.10 \pm 0.02 \Delta$ unit; $P<0.05$ ). Plasma L-arginine: assymetric dimethyl arginine rates was reduced (173 \pm 12 vs. $\left.231 \pm 6 \mu \mathrm{mol} \cdot \mu \mathrm{mol}^{-1}, P<0.05\right)$.

Conclusion: Premenopausal HIV positive women had microvascular oxidative stress with severe endothelial dysfunction and reduced nitric oxide and arginine: assymetric dimethylarginine ratio but enhanced endothelial, thromboxane and endothelin contractions. These microvascular changes may herald later cardiovascular disease.

Keywords: Cardiovascuar disease (CVD); Endothelial dysfunction; Nitric oxide (NO); Endothelium-dependent relaxing factor (EDRF); Reactive oxygen species (ROS); Asymmetric dimethylarginine (ADMA); Thromboxane-prostanoid receptors (TP-Rs); Endothelin-1 (ET-1)

\section{Introduction}

Highly active antiretroviral therapy (HAART) has prolonged the life of those infected with the human immunodeficiency virus (HIV), but sadly, they suffer from an increased burden of many diseases usually encountered in older subjects, such as myocardial infarction [1] and stroke [2], accompanied by carotid artery remodeling and accelerated arteriosclerosis [3]. These complications have been related both to HAART [4] and to HIV infection [3]. Small vessel disease contributes to renal glomerulopathy [5], microvascular dementia [6], congestive cardiac heart failure (CHF) [7] and pulmonary hypertension [8], all of which are commoner in HIV-infected individuals. Subjects with HIV infection have vascular inflammation [9] and endothelial dysfunction as assessed indirectly from brachial artery flow-mediated vasodilatation (FMD) [10]. This has been related in some [11], but not all [10] studies, to HAART or to increased systemic markers of reactive oxygen species (ROS) [12].

We reported that subdermal microvessel dissected from a gluteal skin biopsy from patients with stage 1 chronic kidney disease (CKD), but without overt cardiovascular disease (CVD), had severe microvascular endothelial dysfunction and impaired nitric oxide synthase (NOS) activity [13]. These effects were not detected by brachial artery endothelial-dependent flowmediated dilation [14]. Thus, we have studied subcutaneous microvessels directly to investigate the hypothesis that HIV infection in premenopausal women largely free of CVD risk factors is accompanied by microvascular ROS, endothelial dysfunction and reduced nitric oxide (NO) and enhanced contractility. We investigated: acetylcholine (ACh)-induced endothelium-dependent relaxation (EDR); endothelium-dependent relaxation factor (EDRF; nitric oxide synthase (NOS)-dependent relaxation) and endothelium-dependent hyperpolarizing factor (EDHF; potassium-channel dependent relaxation) and endothelium independent relaxation (EIR; sodium nitroprusside (SNP) relaxation) and related these to microvascular $\mathrm{NO}$ generation and to the plasma ratio of $\mathrm{L}$-arginine to

*Corresponding author: Dan Wang, Division of Nephrology and Hypertension Georgetown University Medical Center Building D, Room 399, 4000 Reservoir Road NW, Washington, DC 20007, USA, Tel: 202-687-0887; Fax: 202-687-4194; E-mail: dw32@georgetown.edu

Received October 30, 2013; Accepted November 27, 2013; Published December 03, 2013

Citation: Wang D, Melancon JK, Verbesey J, Hu H, Liu C, et al. (2013) Microvascular Endothelial Dysfunction and Enhanced Thromboxane and Endothelial Contractility in Patients with HIV. J AIDS Clin Res 4: 267. doi:10.4172/2155-6113.1000267

Copyright: ( 2013 Wang D, et al. This is an open-access article distributed unde the terms of the Creative Commons Attribution License, which permits unrestricted use, distribution, and reproduction in any medium, provided the original author and source are credited. 
asymmetric dimethylarginine (ADMA) which is the NOS substrate and inhibitor respectively. We also investigated the endothelium-dependent contracting factor (EDCF; contractions under spontaneous tone with relaxation pathways inhibited [15].

Patients with HIV have enhanced arterial and venous thromboembolic disease [2,16], coagulation [18] and pulmonary hypertension [8] which have been related to thromboxane-prostanoid receptor (TP-Rs) and/or endothelin 1 (ET-1) signaling [13,19-23]. ROSdependent activation of vascular TP-Rs contributes to vasculopathy, inflammation [24] and atherosclerosis [25], but the roles of ET-1 and TP-R signaling in the vascular disease of patients with HIV infection has not been explored. Therefore, we also studied microvascular contractile responses to the stable TP-R agonist, U-46,619 and to ET-1 and compared these to phenylephrine (PE) which does not cause prominent vascular oxidative stress $[15,26]$.

\section{Materials and Methods}

\section{Study population}

Self-identified African American premenopausal women $(\mathrm{n}=10)$ enrolled in the Metropolitan Washington Women's HIV Study Group (WHIS) who were free of CVD risk factors except for increased body mass index (BMI) and had well-controlled HIV were the test group. All received HAART and all had an HIV viral load $<500$ copies $\mathrm{ml}^{-1}$ within 3 months. The control group $(\mathrm{n}=10)$ was selected from matched healthy African-American premenopausal subjects participating in the WHIS. Exclusion criteria for both groups included: prior stroke, myocardial infarction, kidney or liver disease, dementia, hypertension, diabetes mellitus or endocrine disease, anemia, dyslipidemia, alcoholism or current substance abuse, post-menopausal or ovariectomised state or receiving female sex hormones, a smoker within the last 6 months, abnormal liver function tests, urinalysis or serum creatinine, inability to comprehend the informed consent or requirement for treatment other than HAART.

Subject was given a written consent as approved by the Georgetown University Institutional Review Board. Their seated blood pressure (BP) was measured with an automated apparatus after 15 minutes of rest with a mean of 3 readings. No subject had a $B P \geq 140 / 90 \mathrm{mmHg}$ or a serum creatinine $\geq 1.3 \mathrm{mg} \cdot \mathrm{ml}^{-1}$ or an abnormal urinalysis (except for a trace of protein).

\section{Preparation of small subcutaneous vessels}

A subcutaneous gluteal fat biopsy (approximately $3 \times 0.6 \times 2 \mathrm{~cm}^{3}$ ) was placed without delay in physiological saline solution (PSS) [27] at $4^{\circ} \mathrm{C}$. Small arteries ( 200 to $250 \mu \mathrm{m}$ in diameter) were mounted in two isometric, four chamber Mulvany-Halpern small-vessel myographs (Danish MyoTech, Aarhus, Denmark) [13].

\section{Microvascular protocols}

The resistance vessels were warmed to $37^{\circ} \mathrm{C}$, equilibrated for 30 min, and the internal circumference set to give a wall tension of 0.2 $\mathrm{mN} \cdot \mathrm{mm}^{-2}$ [15]. The myograph chambers were bubbled with $5 \% \mathrm{CO}_{2}$ and $21 \% \mathrm{O}_{2}$ and maintain at $\mathrm{pH}$ of $7.4[15,27]$. Vessels were contracted three times with norepinephrine (NE) $\left(10^{-5} \mathrm{~mol} \cdot \mathrm{l}^{-1}\right)$, followed by one exposure to high-potassium $\left(123 \mathrm{mmol} \cdot \mathrm{l}^{-1}\right)$ solution (KPSS) and finally a repeat exposure to KPSS containing NE $\left(10^{-5} \mathrm{~mol} \cdot \mathrm{l}^{-1}\right.$, NAK). NAK provided the reference contraction [15]. Contractions were maintained for 3 min before rinsing with PSS.

\section{EDR, EDRF, EIR and EDCF responses}

Two vessels were preconstricted with $10^{-5} \mathrm{moll}^{-1} \mathrm{NE}$ and relaxed with acetylcholine (ACh: $10^{-8}$ to $10^{-4} \mathrm{~mol} \mathrm{l}^{-1}$, EDR) or sodium nitroprusside (SNP: $10^{-8}$ to $10^{-3} \mathrm{~mol} \mathrm{l}^{-1}$, EIR). The EDRF response was the relaxation to ACh in PSS (vehicle) minus the same response with $10^{-5} \mathrm{~mol} \mathrm{l}^{-1} \mathrm{~L}$ $\mathrm{N}^{\mathrm{G}}$-nitroarginine methyl ester (L-NAME) to inhibit NOS. The EDHF response was the relaxation to ACh in L-NAME pre-treated vessels minus the response after blockade of calcium activated potassium channels with $10^{-6} \mathrm{~mol} \mathrm{l}^{-1}$ apamin (AP) plus $10^{-5} \mathrm{~mol} \mathrm{l}^{-1}$ charybdotoxin (CTX $10^{-5} \mathrm{~mol} \mathrm{l}^{-1}[15]$. This combination reduced relaxations to $10^{-4} \mathrm{~mol}$ $\mathrm{l}^{-1} \mathrm{ACh}$ to $2 \pm 6 \%$ which was similar to endothelium removed $(3 \pm 4 \%)$. EDCF responses were taken as the contractions to ACh of vessels under spontaneous tone incubated with L-NAME, AP and CTX to block vasodilator pathways.

\section{Contraction to PE, U-46,619 and ET-1}

Two vessels were contracted with graded concentrations of phenylephrine (PE, $10^{-8}$ to $\left.10^{-5} \mathrm{~mol} \mathrm{l}^{-1}\right)$, U-46,619 $\left(10^{-12}\right.$ to $\left.10^{-6} \mathrm{~mol}^{-1}\right)$ or endothelin-1 (ET-1, $10^{-10}$ to $10^{-7} \mathrm{~mol} \mathrm{l}^{-1}$ ).

\section{Time control studies}

NE contractions were similar at the beginning $(85 \pm 4 \%)$ and end (78 $\pm 4 \%$ ) of the experiments and ACh relaxation were unchanged during incubation in PSS for 30, 60 and $120 \mathrm{~min}$ [27] and remained stable over 10 hours (before: $75 \pm 3$ vs. after 10 hours: $70 \pm 5 \%$; NS)

\section{Vascular NO and ROS}

The assessment of NO activity of microvessels was the same as previously described. Vessels were preloaded with $5 \times 10^{-6} \mathrm{~mol} \mathrm{l}^{-1}$ of 4-amino-5-methoxyamino-2', $7^{\prime}$-difluorofluorescein diacetate (DAFFM DA; Invitrogen, Carlsbad, CA) and $10^{-3} \mathrm{~mol} \mathrm{l}^{-1}$ of L-arginine [28].

For ROS activity, vessels were preloaded with 4-(9-acridinecarbonylamino)-2,2,6,6-tetramethylpiperidin- 1-oxyl free radical (TEMPO-9-AC; $10^{-5} \mathrm{~mol} \mathrm{l}^{-1}$, Invitrogen, Carlsbad, CA) [29,30]. One set was prepared for EDCF studies and stimulated with $10^{-4} \mathrm{~mol} \cdot \mathrm{l}^{-1}$ ACh and another set with $10^{-7} \mathrm{~mol} \cdot \mathrm{l}^{-1}$ ET-1. Excitation was set at $360 \mathrm{~nm}$ and emission was isolated at $460 \mathrm{~nm}$. Incubation with PEG superoxide dismutase ( 125 units $\mathrm{ml}^{-1}$ ) prevented $92 \%$ of the fluorescence to ACh in vessels from Ang II-infused rats [30].

\section{Plasma L-arginine, ADMA and symmetric dimethylarginine (SDMA)}

These were measured by Beckman Coulter PACE/MDQ High Performance Capillary Electrophoresis (Fullerton, CA) with Laser Induced Fluorescence Detection (HPCE-LIF) in plasma as previously described [31]. The intra- and inter-assay coefficient of variations was $3.8 \%$ and $4.6 \%$ for ADMA, $4.2 \%$ and $5.2 \%$ for SDMA, and $6 \%$ and $6.5 \%$ for arginine.

\section{Statistical analysis}

Data are presented as mean \pm SEM. Cumulative dose-response experiments were analyzed by nonlinear regression (curve fit) and differences assessed by two-way, repeated-measures ANOVA followed, if appropriate, with Bonferroni post hoct-tests for multiple comparisons. A probability value $<0.05$ was considered statistically significant.

\section{Result}

The two groups were well matched (Table 1). The CD4 count of patients 
Citation: Wang D, Melancon JK, Verbesey J, Hu H, Liu C, et al. (2013) Microvascular Endothelial Dysfunction and Enhanced Thromboxane and Endothelial Contractility in Patients with HIV. J AIDS Clin Res 4: 267. doi:10.4172/2155-6113.1000267

Page 3 of 6

\begin{tabular}{|c|c|c|c|}
\hline Parameter & Controls $(n=10)$ & HIV (n=10) & $P$ value \\
\hline Age (years) & $37 \pm 2$ & $41 \pm 1$ & NS \\
\hline Body Mass Index $\left(\mathbf{k g} \cdot \mathrm{m}^{-2}\right)$ & $36 \pm 4$ & $40 \pm 3$ & NS \\
\hline Duration of HIV (years) & & $10 \pm 1$ & \\
\hline Duration of HAART (years) & & $11 \pm 1$ & \\
\hline CD4+ count $\left(\right.$ cell·ml- $\left.{ }^{-3}\right)$ & $1254 \pm 50$ & $448 \pm 40$ & $<0.001$ \\
\hline Viral load (copies·ml-1) & & $328 \pm 15$ & \\
\hline Systolic BP (mmHg) & $117 \pm 3$ & $106 \pm 3$ & NS \\
\hline Diastolic BP (mmHg) & $77 \pm 2$ & $65 \pm 2.3$ & NS \\
\hline Plasma BUN (mg·dl-1) & $12 \pm 1$ & $11 \pm 1$ & NS \\
\hline Plasma creatinine $\left(\mathrm{mg} \cdot \mathrm{dl}^{-1}\right)$ & $0.80 \pm 0.02$ & $0.75 \pm 0.01$ & NS \\
\hline Total cholesterol $\left(\mathbf{m g} \cdot \mathrm{dl}^{-1}\right)$ & $179 \pm 6$ & $173 \pm 11$ & NS \\
\hline HDL cholesterol $\left(\mathrm{mg} \cdot \mathrm{dl}^{-1}\right)$ & $47 \pm 2$ & $51 \pm 5$ & NS \\
\hline LDL cholesterol (mg·dl-1) & $109 \pm 6$ & $98 \pm 9$ & NS \\
\hline Triglyceride $\left(\mathrm{mg} \cdot \mathrm{dl}^{-1}\right)$ & $117 \pm 34$ & $124 \pm 18$ & NS \\
\hline Plasma glucose $\left(\mathrm{mg} \cdot \mathrm{dl}^{-1}\right)$ & $81 \pm 2$ & $90 \pm 4$ & NS \\
\hline
\end{tabular}

Table 1: Clinical characteristics of study groups (mean \pm SEM).

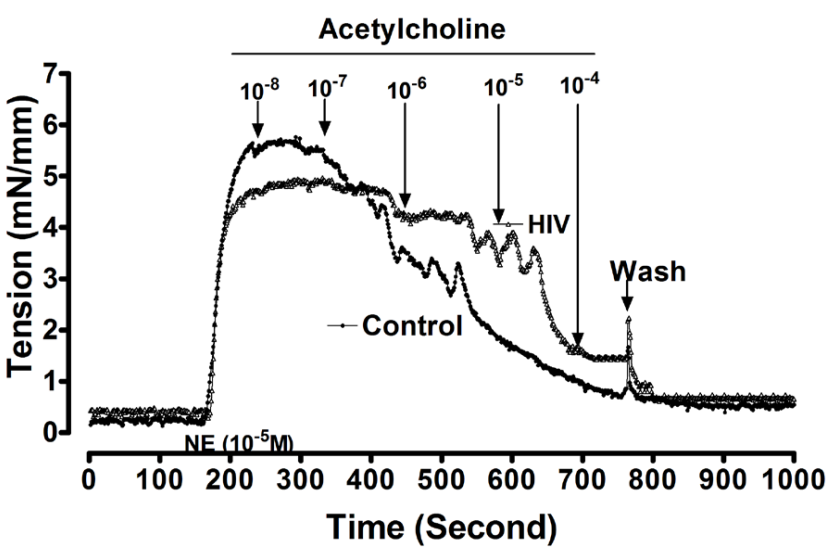

Figure 1: Drawings from myograph tracings of tension in a subcutaneous resistance arteriole from normal subjects (control; solid circles) and a subject infected with HIV (open circles). Norepinephrine (NE) was added to the bath before testing with acetylcholine.

with HIV averaged $448 \pm 40 \mathrm{cell} \cdot \mathrm{ml}^{-3}$. They had been receiving HAART for $\approx 10$ years. Three HIV positive participants had hypertension, which was fully controlled with a single medication that was withheld 14 days before. No subject had blood pressure (BP) $>140 / 90 \mathrm{mmHg}$ on the day of study or more than trace proteinuria and none had an abnormal serum creatinine concentration. The subjects in both groups were free of other cardiovascular risk factor, except for increased body mass index (BMI).

A representative tracing of tension developed by gluteal subdermal microvessels from a control and an HIV-infected patient is shown in Figure 1. NE increased the tension in both vessels. ACh induced a relaxation at $10^{-7} \mathrm{~mol} \cdot \mathrm{l}^{-1}$ in the control vessel and at $10^{-6} \mathrm{~mol} \mathrm{l}^{-1}$ in the vessel from the HIV-infected subject that also had a diminished maximum relaxation.

The group studies of relaxation responses are shown in Figure 2 and Table 2. All relaxation responses to ACh (EDR, EDRF and EDHF) were reduced significantly in subjects with HIV but the EIR to SNP was unchanged.
The EDCF contractions to ACh (Figure 3) and the contractions toU-49,619 and ET-1 (Figure 4 and Table 2) were enhanced in patients with HIV, but the response to PE was unchanged.

The DAF-FM-DA fluorescence (NO activity) with ACh was reduced by $>3$ fold $(\mathrm{P}<0.001)$ in vessels from HIV-infected women (Figure 5A), whereas the ACh- and ET-1-induced increases in tempo9-AC fluorescence (ROS activity) were enhanced by $>2$ fold $(\mathrm{P}<0.01)$ (Figure 5B and 5C).
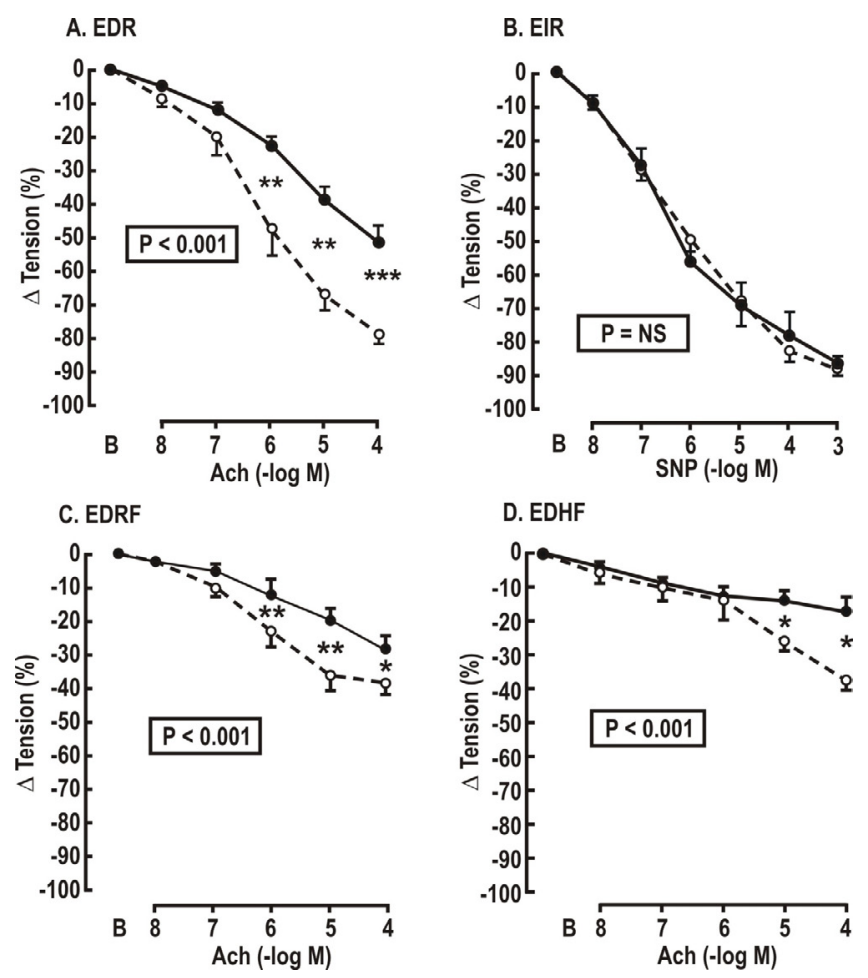

Figure 2: Mean \pm SEM values for acetylcholine- or sodium nitroprussideinduced relaxations of subcutaneous vessels from control (broken lines and open circles) or HIV infected (continuous lines and solids circles) women preconstricted with norepinephrine $\left(\left.10^{-5} \mathrm{~mol} \cdot\right|^{-1}\right)$. Panel $A$ endothelium dependent relaxation (EDR). Panel $B$ endothelium independent relaxation to sodium nitroprusside (EIR). Panel $C$ endothelium dependent relaxation factor responses (EDRF) in vessels incubated with $L-N^{G}$-nitroarginine methy ester $\left(10^{-5} \mathrm{~mol} \cdot l^{-1}\right)$; Panel $D$ endothelium dependent hyperpolarizating factor responses (EDHF) in vessels incubated with L-NAME $\left(10^{-5} \mathrm{~mol} \cdot \cdot^{-1}\right)$ plus apamin (AP, $10^{-6} \mathrm{~mol} \cdot \mathrm{l}^{-1}$ ) and charybotoxin $\left(\mathrm{CTX}, 10^{-5} \mathrm{~mol} \cdot \mathrm{l}^{-1}\right)$. $\mathrm{P}$ values refer to ANOVA with repeated measures. Comparing HIV and control subjects at a single dose: ${ }^{*} \mathrm{P}<0.05,{ }^{\text {"* }} \mathrm{P}<0.01$

\begin{tabular}{|l|c|c|c|}
\hline Variable & Controls (\%) & HIV (\%) & P value \\
\hline EDR & $-78 \pm 3$ & $-51 \pm 6$ & $<0.01$ \\
\hline EDRF & $-39 \pm 3$ & $-28 \pm 4$ & $<0.05$ \\
\hline EDHF & $-37 \pm 4$ & $-17 \pm 4$ & $<0.01$ \\
\hline EIR & $-88 \pm 4$ & $-87 \pm 3$ & NS \\
\hline EDCF & $+7 \pm 2$ & $+21 \pm 6$ & $<0.01$ \\
\hline PE & $+88 \pm 6$ & $+102 \pm 7$ & NS \\
\hline U-46,619 & $+117 \pm 11$ & $+164 \pm 10$ & $<0.01$ \\
\hline ET-1 & $+97 \pm 9$ & $+151 \pm 12$ & $<0.01$ \\
\hline
\end{tabular}

Mean \pm SEM values. Data were obtained from experiments described in Figures $2-4$

Table 2: Maximum changes in vascular tension 


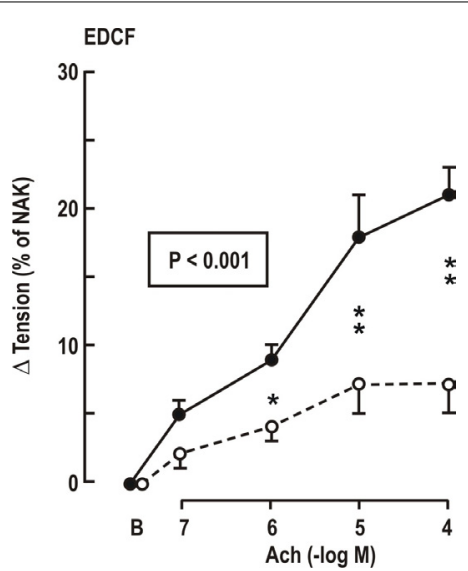

Figure 3: Mean \pm SEM values for endothelium dependent contraction factor responses (EDCF) from controls (broken lines and open circles) or HIV infected (continuous lines and solid circles) women in vessels under spontaneous tone incubated with L-NAME plus apamin+charybotoxin. $P$ values refer to ANOVA with repeated measures. Comparison of HIV and controls at a single dose: ${ }^{*} \mathrm{P}<0.05 ;{ }^{* *} \mathrm{P}<0.01$
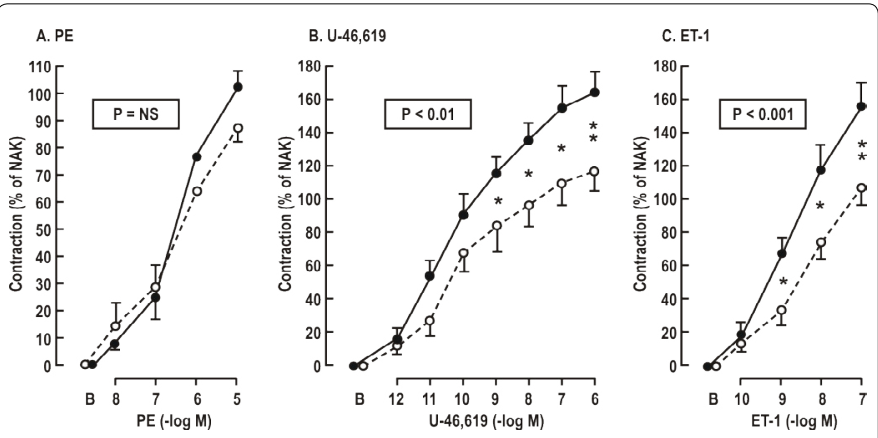

Figure 4: Mean \pm SEM values for vascular contractions to phenylephrine (PE), U-46,619 or endothelin-1(ET-1) from controls (broken lines and open circles) or HIV infected (continuous lines and solid circles) women. $P$ values refer to ANOVA with repeated measures. Comparison of HIV and controls at a single dose: ${ }^{*} \mathrm{P}<0.05$; " $\mathrm{P}<0.01$.

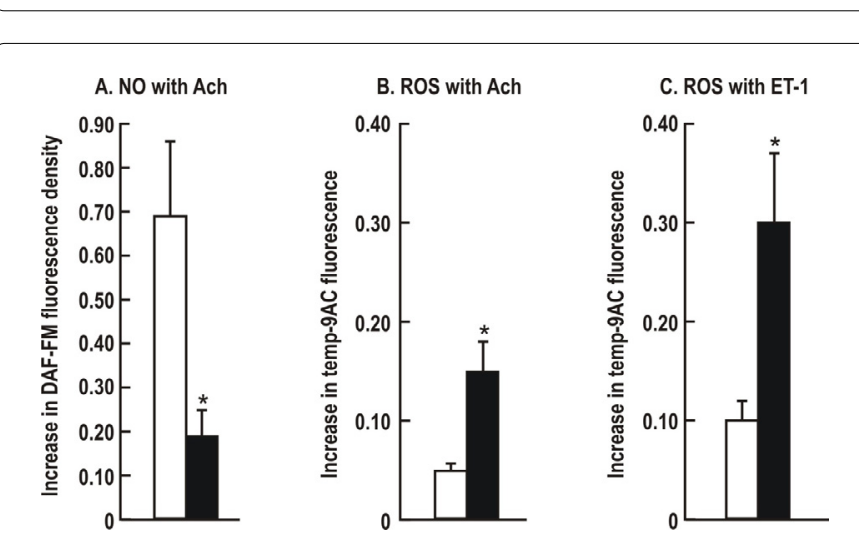

Figure 5: Mean \pm SEM values for $10^{-5} \mathrm{~mol} \cdot \cdot^{-1}$ acetylcholine-induced NO activity (Panel A, DAF-FM fluorescence) and $10^{-4} \mathrm{~mol} \cdot \cdot^{-1} \mathrm{ACh}$ induced ROS activity in the present of L-NAME plus apamin and CTX (Panel B, Tempo-9AC fluorescence) and ROS activity with $10^{-7} \mathrm{~mol} \cdot \mathrm{I}^{-1}$ endothelin-1 (Panel C) of subcutaneous vessels from controls (open boxes) and HIV infected (closed boxes) women. Compared to control: ${ }^{*} \mathrm{P}<0.05$.

The plasma levels of L-arginine, ADMA and SDMA were not different between groups but the L-arginine: ADMA ratio was reduced in women with HIV (Table 3).

\section{Discussion}

This is the first direct assessment of microvascular ROS, endothelial function and NO and TP-R and ET-1 contractility in patients with HIV. The main new findings are that these microvessels had reduced AChinduced endothelium-dependent relaxation (EDR, EDRF and EDHF responses) and plasma arginine: ADMA concentration. The defects in relaxation were endothelium-dependent as the response to the direct acting SNP was not perturbed and the NO activity was reduced. There was also enhanced EDCF responses and enhanced contractions to U-46,619 and to ET- 1 and enhanced ROS generation with the EDCF and the ET-1 contraction. The enhanced contractions were selective since those to $\mathrm{PE}$ were preserved.

All patients were premenopausal, African American women without renal, hepatic, or overt cardiovascular disease except for increased BMI. The infection was well controlled with HAART over 10 years. The two groups were well matched for many factors influencing endothelial function including age, high blood pressure, cholesterol, BMI, blood glucose and serum creatinine. Thus, the abnormal endothelial functioned was not likely related to confounding conditions.

Microvascular ROS and endothelial dysfunction are associated with hypertension [26], but the prevalence of hypertension in HIV has been reported to be reduced [18], unchanged [32] or increased [33]. The absence of hypertension in our subjects, despite endothelial dysfunction, microvascular ROS and enhanced contractility, may relate to depletion of specific CD subsets of T-cells since these patients, although in remission, had diminished CD4 T lymphocyte counts which prevents the development of hypertension in experimental animals [34].

HIV leads to systemic oxidative stress from three sources: HIV infection, shed HIV-related proteins, and HAART [12]. Indirect, brachial artery endothelial-dependent flow-mediated dilation studies concluded that patients with HIV had impaired [10] or intact [35] endothelial function associated with protease inhibitors [11], or independent of HAART [10]. However, conduit artery function [14] does not predict microvascular dysfunction consistently [13,36]. HAART [37] and HIV-1 proteins [12] both caused endothelial dysfunction and oxidative stress in cells or animals. Thus, the enhanced microvascular ROS and endothelial dysfunction in the patients were likely the outcome of prolonged HIV infection and circulating HIV proteins [12], complicated by vascular inflammation and HAART [11].

We confirmed that plasma arginine: ADMA was reduced in HIVinfected patients but our relatively small study did not detect the very modest increase in plasma ADMA reported previously [38]. This reduced arginine: ADMA ratio might impair NOS activity by reducing the substrate: inhibitor ratio, uncoupling NOS to generate $\mathrm{O}_{2}{ }^{--}$, or enhancing endothelial uptake of ADMA [39] and might therefore have contributed to the enhanced microvascular ROS and reduced NO in these vessels. ROS increased ADMA in the vessels of angiotensin II-infused rats without changing plasma levels because of impaired cellular ADMA export [30]. Arginase is increased by inflammation [40]. Thus, the normal plasma

\begin{tabular}{|c|c|c|c|}
\hline Variable & Controls & HIV & $P$ value \\
\hline L-arginine $\left(\mu \mathrm{mol} \mathrm{I}{ }^{-1}\right)$ & $101 \pm 7$ & $85 \pm 6$ & NS \\
\hline ADMA $\left(\mu \mathrm{mol} \mathrm{I} \mathrm{I}^{-1}\right)$ & $0.44 \pm 0.02$ & $0.48 \pm 0.02$ & NS \\
\hline SDMA $\left(\mu \mathrm{mol} \mathrm{I}^{-1}\right)$ & $0.57 \pm 0.05$ & $0.46 \pm 0.02$ & NS \\
\hline L-arginine: ADMA $\left(\mu \mathrm{mol} \cdot \mu \mathrm{mol}^{-1}\right)$ & $231 \pm 6$ & $178 \pm 12$ & $<0.05$ \\
\hline
\end{tabular}

Table 3: Plasma levels of L-arginine, ADMA and SDMA (mean \pm SEM values). 
Citation: Wang D, Melancon JK, Verbesey J, Hu H, Liu C, et al. (2013) Microvascular Endothelial Dysfunction and Enhanced Thromboxane and Endothelial Contractility in Patients with HIV. J AIDS Clin Res 4: 267. doi:10.4172/2155-6113.1000267

Page 5 of 6

ADMA and the decreased plasma arginine: ADMA of the HIV-infected subject are consistent with microvascular ROS and inflammation.

Markers of ROS [26,41], the level of thromboxane metabolites [42,43], and ET-1 [42,44] and expression of TP-R s [45] all are associated with risk factors for chronic renal disease, CVD and vasculopathy. EDCF is generated by ET -1 which stimulates thromboxane $\mathrm{A}_{2}\left(\mathrm{~T} \times \mathrm{A}_{2}\right)$ biosynthesis [46] whereas activation of TP-Rs releases ET-1 [47] and generates ROS $[48,49]$. In turn, ROS are required for microvascular EDCF responses mediated by TP-R [30,50], can enhance responses to TP and ET receptor stimulation [15] and can stabilize TP-Rs in active form [51]. Thus, increases in vascular ROS in HIV may initiate positive feedback interactions that may under lie the enhanced EDCF, TP-R and ET-1responses. Further studies will be required to evaluate these possibilities.

This study has some limitations. First, the sample size is small, but was sufficient to demonstrate statistically robust conclusions. Second, the source of microvascular ROS was not identified. The vessels were fresh vessels dissected from a gluteal biopsy and study of both vascular function and the ROS source would require more blood vessels than were available from a single biopsy. Third, while defective microvascular NO can account for the defective EDRF response, NO does not mediate EDHF response, whose cause was not identified. Fourth, all the women with HIV were treated with HAART which can contribute to endothelial ROS and endothelial dysfunction [12,37]. Few HIV-infected subjects decline HAART, and those that do often have many complications. Thus, the selection of an appropriate untreated control group will be difficult.

In conclusion, this is the first direct demonstration of severe microvascular oxidative stress, endothelial dysfunction and $\mathrm{NO}$ deficiency coupled with enhanced endothelium-dependent contractions and contractions to thromboxane and ET- 1 in HIV positive subjects without overt CVD risk factors except for increased BMI.

\section{Perspective}

HIV increases thromboembolism [12,16] and pulmonary hypertension [8] both of which are related to TP-R signaling [21,22]. ET-1 can cause pulmonary hypertension [19] which is treated by ET receptor blockade [20]. ET-1 is released by ROS or hypoxia from pulmonary endothelial cells [23] and by HAART from blood vessels [52]. Therefore, the increased responsiveness to ET-1 and activation of TP-Rs likely derives from oxidative stress and could contribute to the development of an EDCF and to the increased risk for thromboembolism and pulmonary hypertension in HIV.

CVD likely originates with small-vessel disease [42] which underlies CHF, microvascular dementia, and proteinuric chronic kidney disease and the subsequent development of large vessel diseases that also are prevalent in patients with HIV. Correction of oxidative stress reduced vascular ADMA [30]. Our findings suggest potential therapeutic roles for TP-R or ET-R antagonists for prevention of pulmonary hypertension, thromboembolism, CVD and microvascular diseases in HIV-infected subjects. This could not be obtained by aspirin $[42,53]$. Two current studies suggest this to be urgent. First, in the caliber of the small retinal vessels of HIV infected subjects predicted mortality independent of HAART but no mechanism was identified [54]. Second, prophylactic antiretroviral administration to normal subjects with high risk behavior was recommended for HIV prophylaxis [55]. Since increasing numbers of normal subjects may be exposed to prophylactic antiretroviral therapy for prolonged periods, it is important to develop preventative strategies.

\section{Acknowledgements}

The study was funded by the American Recovery and Reinvestment Act (ARRA) grant from the National Institute of Allergy and Infectious Diseases to the Women's Interagency HIV Study at Georgetown University, Washington DC (U01AI034994-17S1) and a supplemental award from the DC Developmental Center for AIDS Research (DC-CFAR) from the National Institute of Allergy and Infectious Diseases (NIAID) (P30-AI087714), the Federal funds (UL1TR000101) from National Center for Advancing Translational Sciences (NCATS), National Institutes of Health $(\mathrm{NIH})$, through the Clinical and Translational Science Awards Program (CTSA), a trademark of Department of Health and Human Services (DHHS), part of the Roadmap Initiative, "Re-Engineering the Clinical Research Enterprise", Translational Research Pilot Award from the Department of Medicine, Georgetown University and by funds from Marriott Family Research Award.

We thank WHIS for collaboration, Ms. Dorothy Morgan for recruitment, Dao Mai, MD for follow-up of participants and the Georgetown University Clinica Research Unit and the Clinical and Translational Science (GHUCCTS) program for clinical facilities, statistical advice, and assistance with gluteal biopsy and Cheng Wang, MD (Division of Nephrology, The Third Hospital of Sun Yat-sen University, Guangzhou, China) for technical assistance.

\section{References}

1. Sabin CA, Worm SW, Weber R, Reiss P, El-Sadr W, et al. (2008) Use of nucleoside reverse transcriptase inhibitors and risk of myocardial infarction in HIV-infected patients enrolled in the D:A:D study: a multi-cohort collaboration. Lancet 371: 1417-1426.

2. Bozzette SA, Ake CF, Tam HK, Chang SW, Louis TA (2003) Cardiovascular and cerebrovascular events in patients treated for human immunodeficiency virus infection. N Engl J Med 348: 702-710.

3. Hulten E, Mitchell J, Scally J, Gibbs B, Villines TC (2009) HIV positivity, protease inhibitor exposure and subclinical atherosclerosis: a systematic review and meta-analysis of observational studies. Heart 95: 1826-1835.

4. DAD Study Group, Friis-Møller N, Reiss P, Sabin CA, Weber R, et al. (2007) Class of antiretroviral drugs and the risk of myocardial infarction. N Engl J Med 356: 1723-1735.

5. Medapalli RK, He JC, Klotman PE (2011) HIV-associated nephropathy: pathogenesis. Curr Opin Nephrol Hypertens 20: 306-311.

6. Gorelick PB, Scuteri A, Black SE, Decarli C, Greenberg SM, et al. (2011) Vascular contributions to cognitive impairment and dementia: a statement for healthcare professionals from the american heart association/american stroke association. Stroke 42: 2672-2713.

7. Butt AA, Chang CC, Kuller L, Goetz MB, Leaf D, et al. (2011) Risk of heart failure with human immunodeficiency virus in the absence of prior diagnosis of coronary heart disease. Arch Intern Med 171: 737-743.

8. Degano B, Guillaume M, Savale L, Montani D, Jaïs X, et al. (2010) HIVassociated pulmonary arterial hypertension: survival and prognostic factors in the modern therapeutic era. AIDS 24: 67-75.

9. Boger MS, Shintani A, Redhage LA, Mitchell V, Haas DW, et al. (2009) Highly sensitive C-reactive protein, body mass index, and serum lipids in HIV-infected persons receiving antiretroviral therapy: a longitudinal study. J Acquir Immune Defic Syndr 52: 480-487.

10. Blanco JJ, García IS, Cerezo JG, de Rivera JM, Anaya PM, et al. (2006) Endothelial function in HIV-infected patients with low or mild cardiovascular risk. J Antimicrob Chemother 58: 133-139.

11. Shankar SS, Dubé MP, Gorski JC, Klaunig JE, Steinberg HO (2005) Indinavi impairs endothelial function in healthy HIV-negative men. Am Heart J 150: 933.

12. Porter KM, Sutliff RL (2012) HIV-1, reactive oxygen species, and vascular complications. Free Radic Biol Med 53: 143-159.

13. Wang D, Iversen J, Wilcox CS, Strandgaard S (2003) Endothelial dysfunction and reduced nitric oxide in resistance arteries in autosomal-dominant polycystic kidney disease. Kidney Int 64: 1381-1388.

14. Clausen P, Feldt-Rasmussen B, Iversen J, Lange M, Eidemak I, et al. (2006) Flow-associated dilatory capacity of the brachial artery is intact in early autosomal dominant polycystic kidney disease. Am J Nephrol 26: 335-339.

15. Wang D, Chabrashvili T, Wilcox CS (2004) Enhanced contractility of renal afferent arterioles from angiotensin-infused rabbits: roles of oxidative stress, thromboxane prostanoid receptors, and endothelium. Circ Res 94: 1436-1442. 
Citation: Wang D, Melancon JK, Verbesey J, Hu H, Liu C, et al. (2013) Microvascular Endothelial Dysfunction and Enhanced Thromboxane and Endothelial Contractility in Patients with HIV. J AIDS Clin Res 4: 267. doi:10.4172/2155-6113.1000267

16. Malek J, Rogers R, Kufera J, Hirshon JM (2011) Venous thromboembolic disease in the HIV-infected patient. Am J Emerg Med 29: 278-282.

17. Matta F, Yaekoub AY, Stein PD (2008) Human immunodeficiency virus infection and risk of venous thromboembolism. Am J Med Sci 336: 402-406.

18. Armah KA, McGinnis K, Baker J, Gibert C, Butt AA, et al. (2012) HIV status, burden of comorbid disease, and biomarkers of inflammation, altered coagulation, and monocyte activation. Clin Infect Dis 55: 126-136.

19. Nagendran J, Sutendra G, Paterson I, Champion HC, Webster L, et al. (2013) Endothelin axis is upregulated in human and rat right ventricular hypertrophy. Circ Res 112: 347-354.

20. Judge EP, Gaine SP (2013) Management of pulmonary arterial hypertension. Curr Opin Crit Care 19: 44-50.

21. Hirenallur-S DK, Detweiler ND, Haworth ST, Leming JT, Gordon JB, et al. (2012) Furegrelate, a thromboxane synthase inhibitor, blunts the development of pulmonary arterial hypertension in neonatal piglets. Pulm Circ 2: 193-200.

22. Hinton M, Gutsol A, Dakshinamurti S (2007) Thromboxane hypersensitivity in hypoxic pulmonary artery myocytes: altered TP receptor localization and kinetics. Am J Physiol Lung Cell Mol Physiol 292: L654-663.

23. Chen YF, Oparil S (2000) Endothelin and pulmonary hypertension. J Cardiovasc Pharmacol 35: S49-53.

24. Di Wang H, Hope S, Du Y, Quinn MT, Cayatte A, et al. (1999) Paracrine role of adventitial superoxide anion in mediating spontaneous tone of the isolated rat aorta in angiotensin II-induced hypertension. Hypertension 33: 1225-1232.

25. Worth NF, Berry CL, Thomas AC, Campbell JH (2005) S18886, a selective TP receptor antagonist, inhibits development of atherosclerosis in rabbits. Atherosclerosis 183: 65-73.

26. Wilcox CS, Pearlman A (2008) Chemistry and antihypertensive effects of tempol and other nitroxides. Pharmacol Rev 60: 418-469.

27. Wang D, Iversen J, Strandgaard S (2000) Endothelium-dependent relaxation of small resistance vessels is impaired in patients with autosomal dominant polycystic kidney disease. J Am Soc Nephrol 11: 1371-1376.

28. Wang D, Gill P, Chabrashvili T, Onozato ML, Raggio J, et al. (2007) Isoformspecific regulation by $N(G), N(G)$-dimethylarginine dimethylaminohydrolase of rat serum asymmetric dimethylarginine and vascular endothelium-derived relaxing factor/NO. Circ Res 101: 627-635.

29. Fellner SK, Arendshorst WJ (2004) Endothelin A and B receptors of preglomerular vascular smooth muscle cells. Kidney Int 65: 1810-1817.

30. Wang D, Luo Z, Wang X, Jose PA, Falck JR, et al. (2010) Impaired endothelial function and microvascular asymmetrical dimethylarginine in angiotensin IIinfused rats: effects of tempol. Hypertension 56: 950-955

31. Aslam S, Santha T, Leone A, Wilcox C (2006) Effects of amlodipine and valsartan on oxidative stress and plasma methylarginines in end-stage renal disease patients on hemodialysis. Kidney Int 70: 2109-2115.

32. Galli L, Salpietro S, Pellicciotta G, Galliani A, Piatti P, et al. (2012) Risk of type 2 diabetes among HIV-infected and healthy subjects in Italy. Eur J Epidemiol 27: 657-665.

33. Jericó C, Knobel H, Montero M, Sorli ML, Guelar A, et al. (2005) Hypertension in HIV-infected patients: prevalence and related factors. Am J Hypertens 18 : 1396-1401.

34. Marvar PJ, Vinh A, Thabet S, Lob HE, Geem D, et al. (2012) T lymphocytes and vascular inflammation contribute to stress-dependent hypertension. Biol Psychiatry 71: 774-782

35. Lazar JM, Wu X, Shi Q, Kagame A, Cohen M, et al. (2009) Arterial wave reflection in HIV-infected and HIV-uninfected Rwandan women. AIDS Res Hum Retroviruses 25: 877-882.

36. Ghitescu L, Robert M (2002) Diversity in unity: the biochemical composition of the endothelial cell surface varies between the vascular beds. Microsc Res Tech 57: 381-389.

37. Chai H, Yang H, Yan S, Li M, Lin PH, et al. (2005) Effects of 5 HIV protease inhibitors on vasomotor function and superoxide anion production in porcine coronary arteries. J Acquir Immune Defic Syndr 40: 12-19.

38. Kurz K, Teerlink T, Sarcletti M, Weiss G, Zangerle R, et al. (2012) Asymmetric dimethylarginine concentrations decrease in patients with HIV infection under antiretroviral therapy. Antivir Ther 17: 1021-1027.
39. Antoniades $C$, Shirodaria $C$, Leeson $P$ Antonopoulos A, Warrick $N$, et al. (2009) Association of plasma asymmetrical dimethylarginine (ADMA) with elevated vascular superoxide production and endothelial nitric oxide synthase uncoupling: implications for endothelial function in human atherosclerosis. Eur Heart J 30: 1142-1150.

40. Morris SM Jr (2009) Recent advances in arginine metabolism: roles and regulation of the arginases. Br J Pharmacol 157: 922-930.

41. Leopold JA, Loscalzo J (2009) Oxidative risk for atherothrombotic cardiovascular disease. Free Radic Biol Med 47: 1673-1706.

42. Félétou M, Cohen RA, Vanhoutte PM, Verbeuren TJ (2010) TP receptors and oxidative stress hand in hand from endothelial dysfunction to atherosclerosis. Adv Pharmacol 60: 85-106.

43. Mehta JL, Lawson D, Mehta P, Saldeen T (1988) Increased prostacyclin and thromboxane A2 biosynthesis in atherosclerosis. Proc Natl Acad Sci U S A 85 4511-4515.

44. Sedeek MH, Llinas MT, Drummond H, Fortepiani L, Abram SR, et al. (2003) Role of reactive oxygen species in endothelin-induced hypertension. Hypertension 42: $806-810$.

45. Katugampola SD, Davenport AP (2001) Thromboxane receptor density is increased in human cardiovascular disease with evidence for inhibition at therapeutic concentrations by the AT1 receptor antagonist losartan. Br J Pharmacol 134: 1385-1392.

46. Takayasu-Okishio M, Terashita Z, Kondo K (1990) Endothelin-1 and platele activating factor stimulate thromboxane $A 2$ biosynthesis in rat vascular smooth muscle cells. Biochem Pharmacol 40: 2713-2717.

47. Chua CC, Hamdy RC, Chua BH (1996) Regulation of endothelin-1 production by a thromboxane A2 mimetic in rat heart smooth muscle cells. Biochim Biophys Acta 1313: 1-5.

48. Kawada N, Dennehy K, Solis G, Modlinger P, Hamel R, et al. (2004) TP receptors regulate renal hemodynamics during angiotensin II slow pressor response. Am J Physiol Renal Physiol 287: F753-759.

49. Zhang M, Dong Y, Xu J, Xie Z, Wu Y, et al. (2008) Thromboxane receptor activates the AMP-activated protein kinase in vascular smooth muscle cells via hydrogen peroxide. Circ Res 102: 328-337.

50. Wang D, Iversen J, Strandgaard S (1999) Contractility and endotheliumdependent relaxation of resistance vessels in polycystic kidney disease rats. J Vasc Res 36: 502-509.

51. Valentin F, Field MC, Tippins JR (2004) The mechanism of oxidative stress stabilization of the thromboxane receptor in COS-7 cells. J Biol Chem 279: 8316-8324.

52. Hebert VY, Crenshaw BL, Romanoff RL, Ekshyyan VP, Dugas TR (2004) Effects of HIV drug combinations on endothelin-1 and vascular cell proliferation. Cardiovasc Toxicol 4: 117-131.

53. Cayatte AJ, Du Y, Oliver-Krasinski J, Lavielle G, Verbeuren TJ, et al. (2000) The thromboxane receptor antagonist $\mathrm{S} 18886$ but not aspirin inhibits atherogenesis in apo E-deficient mice: evidence that eicosanoids other than thromboxane contribute to atherosclerosis. Arterioscler Thromb Vasc Biol 20: 1724-1728.

54. Gangaputra S, Kalyani PS, Fawzi AA, Van Natta ML, Hubbard LD, et al. (2012) Retinal vessel caliber among people with acquired immunodeficiency syndrome: relationships with disease-associated factors and mortality. Am J Ophthalmol 153: 434-444.

55. Baeten JM, Donnell D, Ndase P, Mugo NR, Campbell JD, et al. (2012) Antiretroviral prophylaxis for HIV prevention in heterosexual men and women. N Engl J Med 367: 399-410. 